\title{
ASSESSMENT OF ATHEROMATOUS PLAQUE BY MULTISLICE COMPUTED TOMOGRAPHY CORONARY ANGIOGRAPHY IN PATIENT WITH ZERO CALCIUM SCORE
}

\author{
By \\ Abd El-Mohsen Mostafa Abou Aalia and Ashraf Al-Amir Abd El-Fattah \\ Cardiology Department, Faculty of Medicine, Al-Azhar University, Cairo, Egypt \\ Corresponding author: Abd El-Mohsen Mostafa Abou Aalia, \\ Mobile: 01004712186, E-mail: abdelmohsen1@ hotmail.com
}

\begin{abstract}
Background: Zero calcium score (CS) is associated with low risk for mortality but not low risk for acute coronary disease developments. Soft plaque is vulnerable to fissuring and rupture.

Objective: To evaluate the frequency of coronary atheromatous plaque in patients with zero CS and the associated risk factors.

Patients and methods: This was a cross-sectional, retrospective study with 235 consecutive individuals with zero CS at Islam Cardiac Center from August 2019 to August 2020. A significance level of 5\% was adopted.

Results: The frequency of atheromatous plaque in coronary arteries in 235 patients with zero CS was $26.81 \%$ (63 individuals). In the subgroup of atheromatous plaque with zero CS, mean age was 58 \pm 28 years, 40 $(63.5 \%)$ were females, $29(46.03 \%)$ hypertensive, $33(52.38 \%)$ diabetics, $31(49.2 \%)$ dyslipidemias, $12(19.05 \%$ had family history of premature coronary artery diseases (CAD), $20(31.75 \%)$ smokers and body mass index (BMI) was 27.64 \pm 1.5 . Fifteen patients $(23.8 \%)$ had obstructive plaques (> 50\%).
\end{abstract}

Conclusions: The frequency of atheromatous plaques with zero CS was high. So, absence of calcification does not exclude the presence of plaques, one fourth of them were obstructive, especially with aged individuals.

Keywords: Cardiovascular Diseases, Plaque, Atheromatous, Coronary Artery Disease, Calcium Score; Risk Factors.

\section{INTRODUCTION}

Coronary artery disease (CAD) is the leading cause of mortality all over the world. Many investigations used for diagnosis and risk stratification of CAD patients that determine the plan for management of those patients (Knuuti et al., 2019).

In the era of advanced technology with plenty of available investigation tools, the patients walk in a dilemma of medical care. In cardiology practice, the big challenge is to choose the appropriate tool for the target patient especially those with subclinical CAD (Mampuya, 2012).

Coronary computed tomography angiography (CCTA) is a non-invasive anatomical tool with high diagnostic capability in detecting atheromatous plaques (either obstructive or nonobstructive) compared to the gold standard invasive coronary angiography. 
CCTA can determine the extent of plaque calcification through calcium scoring (CS) which is a rapid simple screening test that may add also information of atheroma composition. Also, it can be estimated using single photon emission tomography (SPECT) machines during myocardial perfusion study (Gabriel et al., 2018).

Coronary calcification, assessed by CS is used for risk stratification of cardiac patient but those with zero CS still own the chance to have an atherosclerotic plaque, those plaques without calcification but lipid core and fibrous cap is vulnerable one with possibility of plaque fissuring and rupture and acute coronary syndrome development. Severe coronary atherosclerosis with multiple obstructive plaques may be present in coronary vessels with zero calcium score. So, zero $\mathrm{CS}$ is not a good negative test especially in those having atheromatous plaques (Stefanadis et al., 2017).

The aim of this work was to evaluate the frequency of coronary atheromatous plaque in patients with zero $\mathrm{CS}$ and the associated risk factors.

\section{PATIENTS AND METHODS}

This study was a cross-sectional retrospective study carried out from August 2019 to August 2020. Patients were consecutively selected and all subjected to CCTA by referral from their physicians for diagnostic imaging in Islamic Cardiac Center, Al-Azhar University.

History of cardiovascular risk factors were collected from each participant before the test in a special form. Patients with zero calcium score and intermediate risk for coronary artery disease according to Diamond and Forrester method were included in the study (Lavenburg et al., 2019).

Patients were excluded if they underwent percutaneous or surgical myocardial revascularization, previous history of acute coronary syndrome, previous stroke or peripheral vascular disease, atrial fibrillation or frequent extra systole, decompensated heart failure, renal impairment and inadequate breath holding.

CS and CCTA of coronary arteries were performed using a 160-slice scanner of Aquilion Prime 160 ${ }^{\mathrm{TM}}$ (Toshiba $^{\mathrm{TM}}$ Medical Systems Corporation, Otawara, Japan). The patients were on ivabradine 5 mg twice daily for at least 3 days before the test. Heart rates of all patients were determined $1 \mathrm{~h}$ before examinations. If heart rate was $\geq 65 \mathrm{bpm}$, the patient was orally administered $50 \mathrm{mg}$ of oral beta blocker atenolol except those with contraindications to beta-blockers. A 0.5 $\mathrm{mg}$ sublingual dose of nitroglycerin was administered just before the scan. In each patient $60 \mathrm{~mL}$ of iodinated contrast followed by $50 \mathrm{~mL}$ of saline solution was injected. Contrast material administration was controlled by test bolus in the ascending aorta. The scan delay was $12 \mathrm{~s}$. Images were reconstructed immediately after completing the scan to identify motion-free coronary artery artifacts. The reconstructed CT image data were transferred to a computer workstation for post-processing, including axial, multiplanar reformat, maximum intensity projection. In all individuals, irrespective of the image quality, every arterial segment was scored in an intent-todiagnose fashion. 
CS analysis was carried out with noncontrast CT using a longitudinal scan coverage from the level of the tracheal bifurcation to the superior border of cardiac silhouette, this including the whole diaphragm to evaluate the whole cardiac area.

The study was done in two phases: 1 st CS was done by the Agatston score. Coronary calcification was defined by the presence of a lesion, its area greater than 1 $\mathrm{mm} 2$, and with the peak intensity equal to or greater than 130 Hounsfield Units (HU). The software automatically identify this and mark it with colors (Gabriel et al., 2018).

In the second phase, CCTA was done if calcium score is zero. Field of view (FOV) construction, voltage $120 \mathrm{kv}$ and 400 miliamperes. $60 \mathrm{~mL}$ iodinated contrast media was administered intravenously through large bore cannula to patients still positioned on the table followed by 50 of saline.

Images were reconstructed immediately after completing the scan to identify motion-free coronary artery artifacts. The reconstructed CT image data were transferred to a computer workstation for post processing. In all individuals, irrespective of the image quality, every arterial segment was scored in an intent-to-diagnose fashion (Kim et al., 2015).

The presence of atheromatous soft plaque was examined only in vessels with a luminal diameter larger than $2 \mathrm{~mm}$, divided into 16 segments. The segment involvement score (SIS) was calculated as the total number of coronary artery segments exhibiting plaque, irrespective of the degree of luminal stenosis within each segment (minimum $=0$; maximum $=$ 16) (Gabriel et al., 2018).

\section{Statistical analysis:}

Quantitative variables were described as mean and standard deviation. Qualitative data were expressed as frequency and parentage. Normality of the sample were ssessed by KolmogorovSmirnov test. According to data normality, the Student's t-test was used for independent groups. The chi-square test was used for categorical variables. The data were analyzed statistically using IBM-SPSS-22 (Statistical Package for the Social Sciences version 22). The test was considered significant if the probability (p-value) was less than 0.05 . 


\section{RESULTS}

In the period of the study, 235 patients had Zero Calcium score. Age of patients was $56.87 \pm 10.22$ years, $66 \%$ were female, $47.7 \%$ hypertensive, $51.9 \%$ diabetics,
$48.9 \%$ dyslipidemias, $35.7 \%$ smokers, and $22.6 \%$ family history of premature CAD with BMI was $27.59 \pm 1.56$ (Table 1).

Table (1): Clinical characters of the studied population

\begin{tabular}{|c|c|}
\hline Variables & Number \\
\hline Age (years) & $56.87 \pm 10.22$ \\
\hline Female sex (\%) & $155(66 \%)$ \\
\hline Hypertension (\%) & $112(47.7 \%)$ \\
\hline Diabetes mellitus (\%) & $122(51.9 \%)$ \\
\hline Dyslipidemia (\%) & $115(48.9 \%)$ \\
\hline Family history of CAD (\%) & $53(22.6 \%)$ \\
\hline Smoking (\%) & $84(35.7 \%)$ \\
\hline Body mass index (kg/m $\left.{ }^{2}\right)$ & $27.59 \pm 1.56$ \\
\hline
\end{tabular}

CAD: coronary artery disease.

Atheromatous plaques were present in 63 patients $(26.81 \%)$. The mean age of them was $58.28 \pm 10.05$ years, $63.5 \%$ were females, $46.03 \%$ hypertensive, $52.38 \%$ diabetics, $49.2 \%$ dyslipidemias, $31.75 \%$ were smokers, $19.05 \%$ had history of family history of premature coronary artery disease and BMI was 27.64 \pm 1.5 . No significant difference between those with plaques and without plaques regarding risk factors part from significant old age in patients with zero CS and atheromatous plaques. Presence of obstructive lesions more than $50 \%$ of the vessel lumen present in $23.8 \%(15 / 63)$ of cases with atheromatous plaques $(6.4 \%$ of total population with zero calcium score). The distribution of obstructive plaques were 10 patients had one segment, 2 patients had two segments and 3 patients had more than two segments stenosis. While non-obstructive lesions in $76.2 \%$ (48/63) of patients, distributed as the following: a- in one segment 19 patients, b- two segments in 21 patients and cmore than two segments in 8 patients (Table 2).

Table (2): Clinical characters of patients according to atheromatous plaques presence

\begin{tabular}{|l|c|c|c|}
\hline \multicolumn{1}{|c|}{ Groups } & $\begin{array}{c}\text { Atheromatous } \\
\text { plaques } \\
\text { Parameters }\end{array}$ & $\begin{array}{c}\text { Zero Calcium } \\
\text { score without } \\
\text { plaques }(\mathbf{n = 1 7 2})\end{array}$ & P value \\
\hline Age (years) & $\mathbf{5 8 . 2 8} \pm \mathbf{1 0 . 0 5}$ & $52.90 \pm 11.10$ & 0.001 \\
\hline Female sex (\%) & $\mathbf{4 0}(\mathbf{6 3 . 5 \%})$ & $\mathbf{1 1 5}(\mathbf{6 6 . 8 6 \% )}$ & $>0.05$ \\
\hline Hypertension (\%) & $\mathbf{2 9}(\mathbf{4 6 . 0 3 \% )}$ & $\mathbf{8 3}(\mathbf{4 8 . 2 6 \%})$ & $>0.05$ \\
\hline Diabetes mellitus (\%) & $\mathbf{3 3 ( 5 2 . 3 8 \% )}$ & $\mathbf{8 9}(\mathbf{5 1 . 7 4 \% )}$ & $>0.05$ \\
\hline Dyslipidemia (\%) & $\mathbf{3 1}(\mathbf{4 9 . 2 \% )}$ & $\mathbf{8 4}(\mathbf{4 8 . 8 4 \% )}$ & $>0.05$ \\
\hline Family history of CAD $(\%)$ & $\mathbf{1 2}(\mathbf{1 9 . 0 5 \% )}$ & $\mathbf{4 1}(\mathbf{2 3 . 8 4 \% )}$ & $>0.05$ \\
\hline Smoking (\%) & $\mathbf{2 0}(\mathbf{3 1 . 7 5 \% )}$ & $\mathbf{6 4}(\mathbf{3 7 . 2 1 \%} \%$ & $>0.05$ \\
\hline Body mass index $\left(\mathrm{kg} / \mathrm{m}^{2}\right)$ & $27.64 \pm 1.50$ & $27.44 \pm 1.71$ & $>0.05$ \\
\hline
\end{tabular}


The most affected segments in the distribution were of the left anterior descending artery $(32 / 63)$, while the least affected vessel is the left circumflex in 11 segments only, and no left main reported affection. Two cases were presented in Figure (1\& 2).

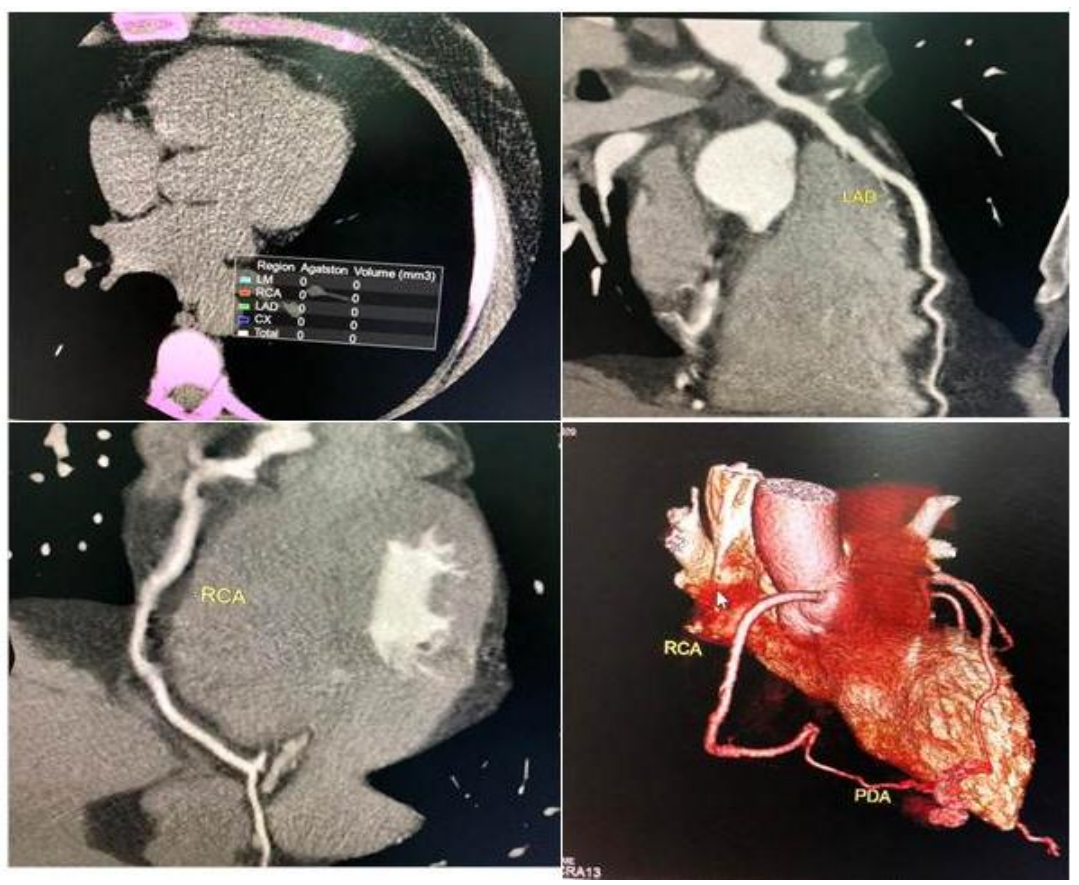

Figure (1): Calcium score zero in a patient with non-obstructive atheromatous soft plaque in distal LAD and proximal RCA.
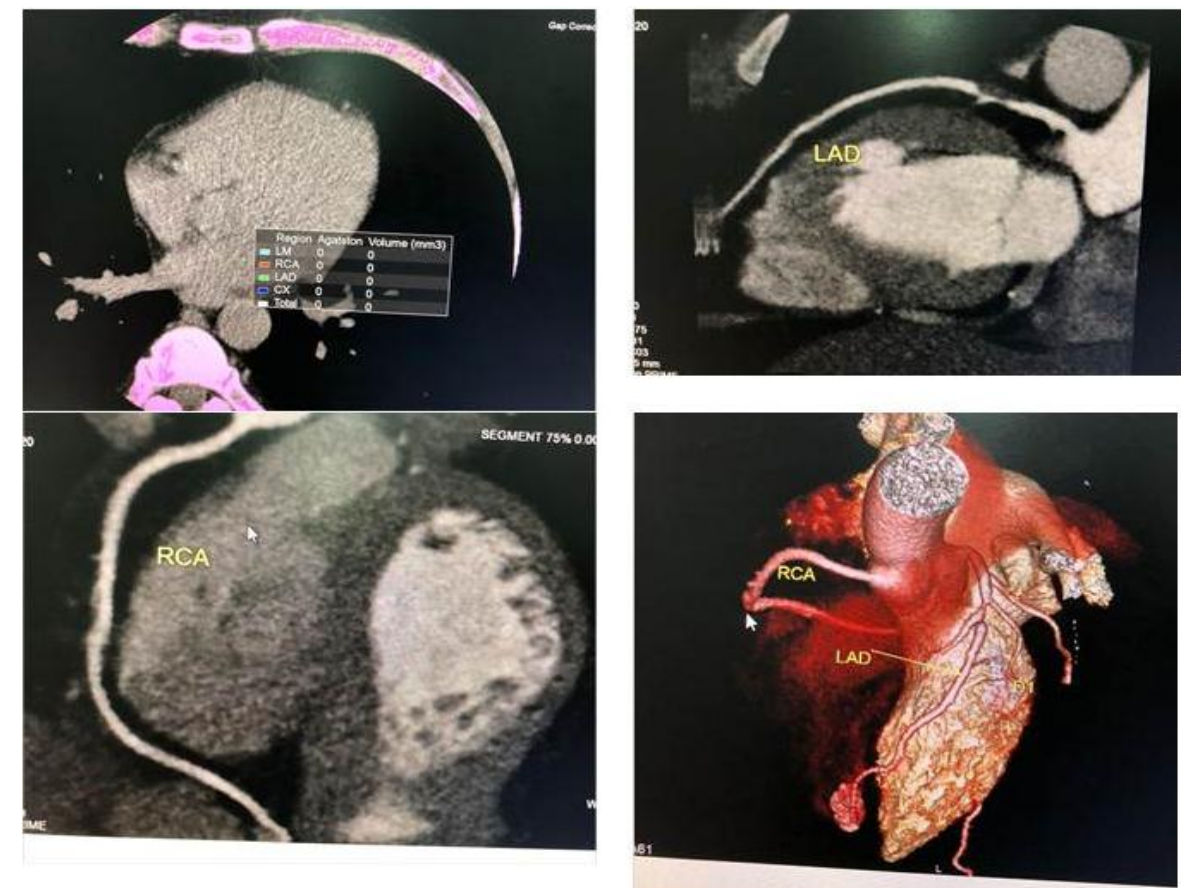

Figure (2): Calcium score zero in a patient with an obstructive atheromatous soft plaque in mid LAD. 
In comparing lipid profile between those with atheromatous plaques and without plaques, no significant difference between both groups although slight elevation in those with plaques (Table 3).

Table (3): Lipid profile of patients according to atheromatous plaques presence.

\begin{tabular}{|c|c|c|c|}
\hline Groups & $\begin{array}{c}\text { Atheromatous } \\
\text { plaques (n=63) }\end{array}$ & $\begin{array}{c}\text { Zero Calcium } \\
\text { score without } \\
\text { plaques (n=172) }\end{array}$ & P value \\
\hline Parameters & $219.61 \pm 36.82$ & $213.35 \pm 46.56$ & $>0.05$ \\
\hline TC (mg \%) & $163.64 \pm 39.80$ & $152.48 \pm 37.94$ & $<0.05$ \\
\hline HDL (mg \%) $(\mathbf{m g} \%)$ & $39.94 \pm 10.26$ & $42.03 \pm 10.19$ & $>0.05$ \\
\hline TG (mg \%) & $172.84 \pm 30.46$ & $165.60 \pm 24.73$ & $>0.05$ \\
\hline Risk ratio & $4.41 \pm 1.62$ & $3.94 \pm 1.58$ & $<0.05$ \\
\hline
\end{tabular}

\section{DISCUSSION}

With the growing development of modern technology in the last decade, the role of CCTA is increasing and the role of $\mathrm{CS}$ in preventive cardiology is expanding (Piepoli et al., 2016). Lack of calcification of coronary tree associated with low vascular aging compared to the same coronary state with calcification and zero CS was reported to have warranty against mortality in western and Asian trials varied between 5 to 15 years (Pechlivanis et al., 2020). Zero calcium score does not mean no atherosclerosis, instead it can be used as risk stratification method. Atherosclerosis process is ended by calcification which is protective to the plaque, before calcification atherosclerosis process occur with vulnerable plaque prone to fissuring and development of acute coronary syndrome as proved by autopsy studied and optical coherence tomography (OCT) and intravascular ultrasound study (IVUS) (Merghani et al., 2017). Also, zero calcium study is not stationary process with follow up revealed increase of calcification and increased risk (Shen et al., 2020).

The main finding of this study was the significant presence of atheromatous plaques $(26.81 \%)$ of those patients with zero calcium score. One fourth of them $(6.4 \%)$ were obstructive (equal or more than $50 \%$ stenosis). No significant difference of risk factor predict the atheromatous plaque presence except old age and slight elevation of low density lipoprotein cholesterol (LDL-C) which are predictors of atheroma development.

When follow the previous studies, there is lack of agreement about the prevalence with wide range due to lack of fixing variables like symptoms, risk factors and indication of the test. This made some unavoidable bias. Gabriel et al. (2018) found the plaque were $9.3 \%$ but they choose obstructive coronary plaque ( $\geq 50 \%$ reduction of luminal diameter) in 4 different centers with different machines. Moradi and Varasteh (2016) stated that $4.1 \%$ of patients with zero CS had atheromatous plaque at CCTA.

Villines et al. (2011) in the CONFIRM study found that $13 \%$ for plaques showed less than $50 \%$ obstruction and $3.5 \%$ showed greater than $50 \%$ obstruction. Also, Kim et al. (2015) in their multicentric cohort study (a CORE64 substudy) confirmed that $19 \%$ of zero CS patients had stenosis $\geq 50 \%$ but when followed they found that $13 \%$ of them required revascularization. So, zero 
calcium score does not exclude the need for revascularization later on.

On the other hand, when choose the candidates presented with acute chest pain present in the emergency departments the prevalence may reach up to $39 \%$ in patients with zero calcium score (Pursnani et al., 2015), although these samples is different from outpatient services of stable chest pain either typical or atypical.

In this study, the variables of predisposition to plaque were aging and LDL level which was different from literature studies as the samples were heterogeneous in between different studies with many ethnic and risk factor variations. So, trials found alcohol intake is a predictor which was fortunately not present in our study populations due to our Islamic and social issues.

Previous studies on obesity had suggested its protective role for CAD (obesity paradox) that not appear in our study, but this could be explained by not use abdominal obesity with accompanied subcutaneous fat in concern rather than BMI (Parsa and Jahanshahi, 2015). Inclusion of asymptomatic individuals may change the percentage of atheromatous plaque.

The data on risk factors apart from lipid profile were obtained by questionnaires from the patients and abdominal obesity not taken into concern. Also, no study of the effect of long standing statin on atheromatous plaques calcifications and complications.

\section{CONCLUSION}

The prevalence of atheromatous plaques is high in patients with zero calcium score, and one fourth of them obstruct more than half of luminal diameter. Absence of coronary calcification does not rule out coronary atherosclerosis especially in old age and high LDL levels. Instead, it made them vulnerable to complications and primary prevention using statins in them may have a role.

\section{REFERENCES}

1. Gabriel, F. S., Gonçalves, L., Melo, E. V., Sousa, A., Pinto, I., Santana, S., Matos, C., Souto, M., Conceição, F. and Oliveira, J. (2018): Atherosclerotic Plaque in Patients with Zero Calcium Score at Coronary Computed Tomography Angiography. Arquivos Brasileiros de Cardiologia, 110(5): 420-427.

2. Kim, J. J., Hwang, B. H., Choi, I. J., Choo, E. H., Lim, S., Kim, J. K., Koh, Y. S., Kim, D. B., Jang, S. W., Cho, E. J., Lee, J. M., Kim, P. J., Cho, J. H., Jung, J. I., Seung, K. B., Min, J. K. and Chang, K. (2015): Impact of diabetes duration on the extent and severity of coronary atheroma burden and long-term clinical outcome in asymptomatic type 2 diabetic patients: evaluation by Coronary CT angiography. European Heart Journal Cardiovascular Imaging, 16(10): 1065-1073.

3. Knuuti, J., Wijns, W., Saraste, A., Capodanno, D., Barbato, E., FunckBrentano, C., Prescott, E., Storey, R., Deaton, C., Cuisset, T., Agewall , S., Dickstein, K., Edvardsen, T., Escaned, J., Gersh, B., J., Svitil, P., Gilard, M., Hasdai, D., Hatala, R., Mahfoud, F., Masip, J., Muneretto, C., Valgimigli, M., Achenbach, S. and Bax, J., J., (2019): ESC Scientific Document Group, 2019 ESC Guidelines for the diagnosis and management of chronic coronary syndromes: The Task Force for the diagnosis and management of chronic coronary syndromes of the European Society of Cardiology (ESC). European Heart Journal, 41(3):407-477.

4. Lavenburg, P., Cantor, G., Agunloye, O., Bhagat, A., Taub, E. and Teressa, G. 


\section{ABD EL-MOHSEN MOSTAFA ABOU AALIA et al.,}

(2019): Diagnostic and prognostic role of the modified Diamond-Forrester Model in combination with coronary calcium score in acute chest pain patients. Critical Pathways in Cardiology, 18(1): 32-39.

5. Mampuya, W.M. (2012): Cardiac rehabilitation past, present and future: an overview. Cardiovasc Diagn Ther., 2(1):3849.

6. Merghani, A., Maestrini, V., Rosmini, S., Cox, A. T., Dhutia, H., Bastiaenan, R., David, S., Yeo, T. J., Narain, R., Malhotra, A., Papadakis, M., Wilson, M. G., Tome, M., AlFakih, K., Moon, J. C. and Sharma, S. (2017): Prevalence of Subclinical Coronary Artery Disease in Masters Endurance Athletes with a Low Atherosclerotic Risk Profile. Circulation, 136(2): 126-137.

7. Moradi, M. and Varasteh, E. (2016): Coronary atherosclerosis evaluation among Iranian patients with zero coronary calcium score in computed tomography coronary angiography. Adv Biomed Res., 08(5):24-29.

8. Parsa, A. F. and Jahanshahi, B. (2015): Is the relationship of body mass index to severity of coronary artery disease different from that of waist-to-hip ratio and severity of coronary artery disease? Paradoxical findings. Cardiovascular Journal of Africa, 26(1): 1316.

9. Pechlivanis, S., Moebus, S., Lehmann, N., Erbel, R., Mahabadi, A. A., Hoffmann, P., Jöckel, K. H., Nöthen, M. M., Bachmann, H. S. and Heinz Nixdorf Recall Study Investigative Group (2020): Genetic risk scores for coronary artery disease and its traditional risk factors: Their role in the progression of coronary artery calcificationResults of the Heinz Nixdorf Recall study. PloS one, 15(5): e0232735.

10. Piepoli, M. F., Hoes, A. W., Agewall, S., Albus, C., Brotons, C., Catapano, A. L., Cooney, M. T., Corrà, U., Cosyns, B., Deaton, C., Graham, I., Hall, M. S., Hobbs, F., Løchen, M. L., Löllgen, H., MarquesVidal, P., Perk, J., Prescott, E., Redon, J. and Richter, D. J. (2016): European Guidelines on cardiovascular disease prevention in clinical practice: The Sixth Joint Task Force of the European Society of Cardiology and Other Societies on Cardiovascular Disease Prevention in Clinical Practice (constituted by representatives of 10 societies and by invited experts)Developed with the special contribution of the European Association for Cardiovascular Prevention \& Rehabilitation (EACPR). European Heart Journal, 37(29): 2315-2381.

11. Pursnani, A., Chou, E. T., Zakroysky, P., Deaño, R. C., Mamuya, W. S., Woodard, P. K., Nagurney, J. T., Fleg, J. L., Lee, H., Schoenfeld, D., Udelson, J. E., Hoffmann, U. and Truong, Q. A. (2015): Use of coronary artery calcium scanning beyond coronary computed tomographic angiography in the emergency department evaluation for acute chest pain: the ROMICAT II trial. Circulation, Cardiovascular Imaging, 8(3): $\mathrm{e} 002225$.

12. Shen, Y. W., Wu, Y. J., Hung, Y. C., Hsiao, C. C., Chan, S. H., Mar, G. Y., Wu, M. T. and Wu, F. Z. (2020): Natural course of coronary artery calcium progression in Asian population with an initial score of zero. BMC Cardiovascular Disorders, 20(1): 212-220.

13. Stefanadis, C., Antoniou, C. K., Tsiachris, D. and Pietri, P. (2017): Coronary Atherosclerotic Vulnerable Plaque: Current Perspectives. Journal of the American Heart Association, 6(3): e005543.

14. Villines, T. C., Hulten, E. A., Shaw, L. J., Goyal, M., Dunning, A., Achenbach, S., AlMallah, M., Berman, D. S., Budoff, M. J., Cademartiri, F., Callister, T. Q., Chang, H. J., Cheng, V. Y., Chinnaiyan, K., Chow, B. J., Delago, A., Hadamitzky, M., Hausleiter, J., Kaufmann, P. and Lin, F. Y. (2011): Confirm Registry Prevalence and severity of coronary artery disease and adverse events among symptomatic patients with coronary artery calcification scores of zero undergoing coronary computed tomography angiography: results from the CONFIRM (Coronary CT Angiography Evaluation for Clinical Outcomes: An International Multicenter) registry. Journal of the American College of Cardiology, 58(24): 2533-2540. 


\section{تقييم اللويحة الدهنية للثر ايين التاجية بو اسطة التصوير} المقطعي متعدد الثر ائح في مرضيى درجة الكالسيوم الصفرية عبدالمحسن مصطفى أبو عاليه، أشرف الأمير عبد الفتاح قسم القلب والأوعية الاموية، كلية الطب، جامعة الأزهر بالقاهرة

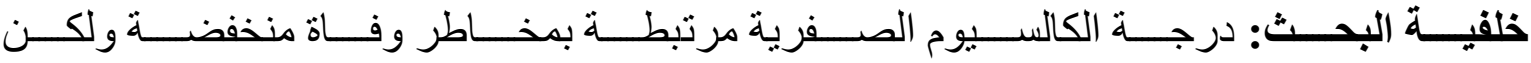

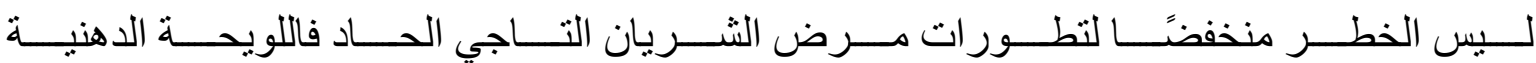
تكون أكثر عرضة للتثقق و التمزق.

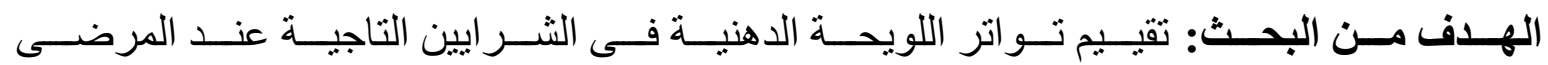
ذوى درجة الكالسيوم صفر و علاقة ذلك بعو امل الخطورة.

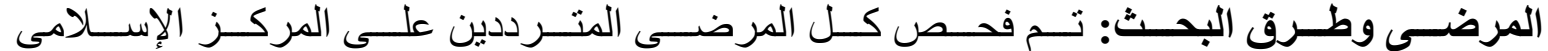

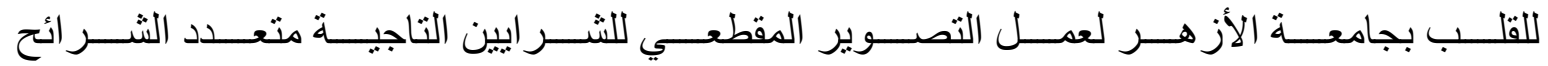

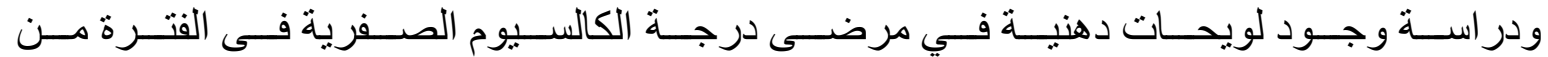

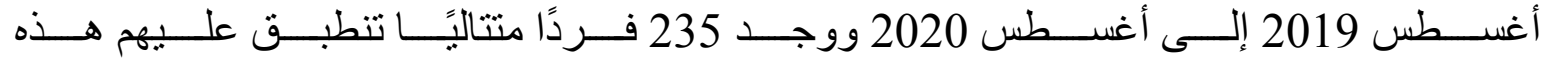

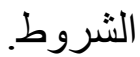

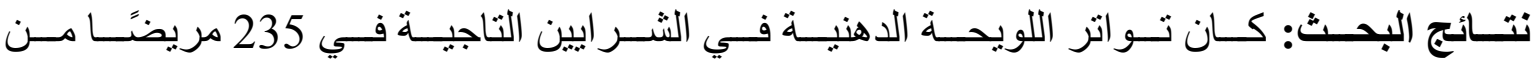

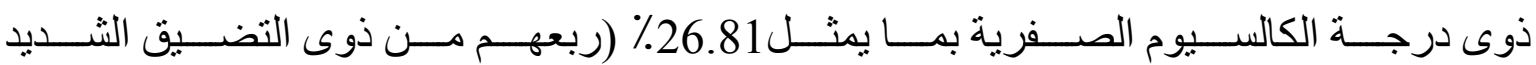

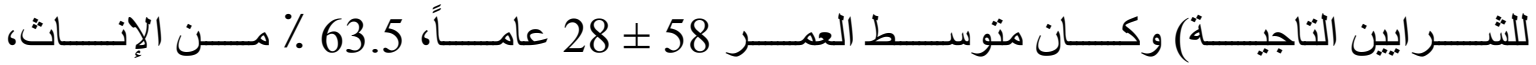

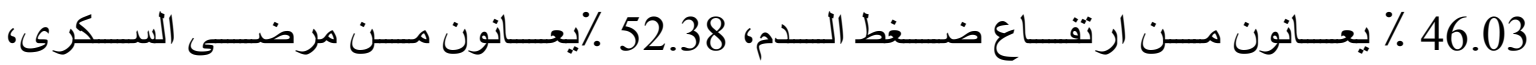

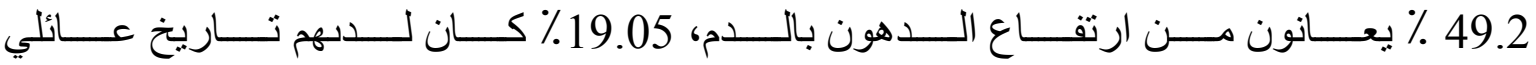

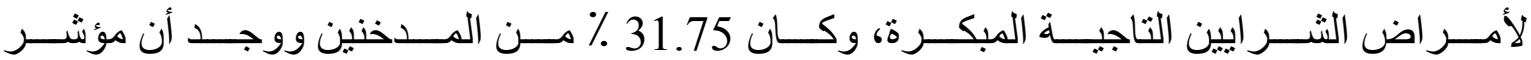

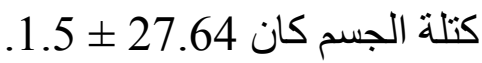

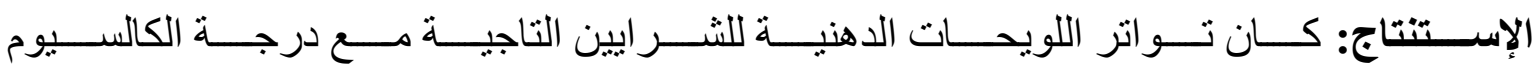

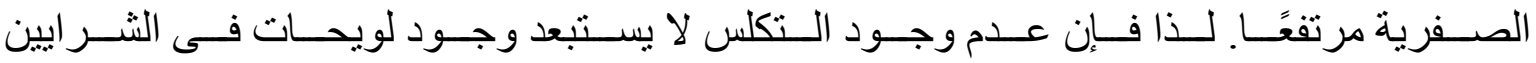

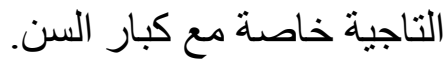

